\title{
Patient Advocacy and the Affordable Care Act: The Growing Need for Nurses to Be Culturally Aware
}

\author{
Edward D. Ronnebaum, Carol Schmer \\ School of Nursing, University of Missouri Kansas City (UMKC), Kansas City, MO, USA \\ Email: eronneb1@jccc.edu
}

Received 8 March 2015; accepted 22 March 2015; published 27 March 2015

Copyright (C) 2015 by authors and Scientific Research Publishing Inc.

This work is licensed under the Creative Commons Attribution International License (CC BY). http://creativecommons.org/licenses/by/4.0/

\section{(c) (i) Open Access}

\section{Abstract}

The nurse-patient relationship is centered on patient advocacy. Patient advocacy is essential in providing individualized care and improving health outcomes. With the recent implementation of the Affordable Care Act, the patient advocacy concept requires further exploration. Published literature involving patient advocacy's history, uses, definition, past analyses and nursing perceptions were examined. Outcomes of this literature review lead to further examining patient advocacy and how it is applied to culturally diverse patient populations, patient advocacy in nursing curricula and related research. Overall study results indicate that patient advocacy is associated with enhanced health encounters that include nurses presenting patients with understandable healthcare options and supporting patients with their healthcare preference. Although, this review identified positive outcomes of patient advocacy, nursing research must be directed toward creating a patient advocacy definition and measuring advocacy from a patient's perspective. There is also a need for nursing leaders to consider placing a higher emphasis on cultural awareness research and education due to an increased rate of culturally diverse patients now seeking care through the Affordable Care Act.

\section{Keywords}

Patient Advocacy, Nursing Perceptions, Cultural Awareness, Affordable Care Act

\section{Introduction}

In recent years, the concept of patient advocacy has become an important topic in healthcare. Patient advocacy is necessary because patients are confronted with healthcare challenges that include comprehending a new diagno- 
sis, understanding difficult medical terms, and recognizing the need for follow-up and preventive care [1]. Patient advocacy includes many interventions such as explaining healthcare options, instructing patients about different procedures and treatments, and clarifying healthcare goals [2] [3]. By providing patient advocacy, nurses establish trust within the nurse-patient relationship, recognize individual patient needs, and promote the patient's active participation in healthcare decisions.

\section{Purpose}

The purpose of this literature review was to examine the history, uses, definition, past analyses and how nurses perceive the patient advocacy concept. Further analysis examined how patient advocacy is applied to culturally diverse patient populations, how patient advocacy is integrated in nursing curricula, measurements for patient advocacy and related research. Insight into how other disciplines recognize, define, and use the concept of advocacy was also explored. This review identifies gaps in the current literature associated with patient advocacy, and provides recommendations to further advance this concept in nursing research and education especially with the newly implemented Affordable Care Act.

\section{Methods of Research}

Search terms including patient advocacy, nursing perspectives, and cultural awareness (separately and combination) were electronically searched through Pub Med and Cumulative Index to Nursing and Allied Health Literature (CINAHL) databases. Articles published in English, from January 1, 1985-June 30, 2014 were reviewed. Inclusion criteria were based on published literature (both clinic research and meta review) involving patient advocacy historical content, usages, definition, past analyses, how nurses perceive the patient advocacy concept, how it is applied to culturally diverse patient populations, patient advocacy in nursing curricula and patient advocacy measurements. Data extraction involved article abstracts, research findings, discussions, conclusions and nursing implications.

The concept of advocacy in non-nursing professions was also included in this literature review. Multiple databases including Lexis Nexis Academic, the Psychology and Behavioral Sciences Collection, and Sociological Abstracts were utilized. References relevant to this analysis were reviewed and selected based on the definition and related research of the concept of advocacy within these selected professions.

\section{Results of Research}

\subsection{Patient Advocacy History}

The concept of patient advocacy can be traced to the Crimean War that occurred between 1853 and 1856 [4] [5]. During that time, Florence Nightingale described the importance of creating a healthcare environment that promoted ventilation, cleanliness, comfort, and sanitation. Promoting these conditions provided patient care settings that led to improved health outcomes [6].

In 1926, the American Nurses Association (ANA), presented nursing's Code of Ethics that established the goals, values and obligations of this profession. The Code of Ethics includes nine provisions; particular to this research is provision three that includes the statement:

The nurse promotes, advocates for, and strives to protect the health, safety, and rights of the patient [7].

In 1976, the ANA's Code for Nurses was changed to emphasize the need for nurses to become more autonomous in their provision of patient care and less as extensions of physicians.

Code alterations included the statement:

In the role of client advocate, the nurse must be alert to and take appropriate action regarding any instances of incompetent, unethical or illegal practice(s) by any member of the healthcare team or the healthcare system itself, or any action on the part of others that is prejudicial to the client's best interest [8].

Since these changes, nurses have continued to refine their patient advocate role to include responsibilities such as protecting patient rights, informing patients about healthcare options, and respecting their patient's healthcare decisions.

Nurse scientists have created philosophical models that reflect the importance of the professional nurse in the patient advocacy role. These models include: focusing on respecting a patient's self-determination in making healthcare decisions, the importance of providing patients with all necessary information needed to make 
healthcare decisions, emphasizing the nurse-patient relationship as a common bond of humanity, and valuing the patient as someone to be cared for and assisted [2] [9]-[11].

\subsection{Current Common Usages}

The term patient advocacy has many meanings and usages. In nursing literature, the patient advocate role is an essential element of care and is commonly described as representing another or intervening on behalf of patients [12]. Other essential advocacy roles noted in nursing literature include providing healthcare information to patients and their families for self-care and follow-up guidance upon discharge or simply acting on behalf of patients [13] [14].

Various disciplines outside of nursing have different meanings for advocacy. A legal definition of advocacy is "the act of pleading or arguing in favor of something, such as a cause, idea or policy; active support" [15]. Law applies advocacy from perspectives such as human rights and poverty discrimination [16] [17].

Psychology defines advocacy as "support or urge by argument, especially publicly; and a person who speaks or writes in support of a cause" [18]. This advocacy definition is then extended to focus "on the behalf of the discipline of psychology, on behalf of the profession and clients, and on the behalf of underserved populations" [18]. Psychological studies that involve the concept of advocacy include examining the effects of advocacy intervention programs or analyzing the outcomes of community-based advocacy practices [19].

Within the discipline of sociology, published research involving a social advocacy definition or the meaning of social advocacy is somewhat limited. However, some research does exist that connects sociology and the influence of advocacy groups in the U.S. political process [20].

\subsection{Patient Advocacy Definition}

This literature review did not identify a generally accepted definition of patient advocacy within the nursing profession. However, research has been conducted with the term nursing advocacy; defined as "communicating with and informing patients, protecting patients, speaking out for patients and building relationships with patients" [21].

\subsection{Patient Advocacy Analyses}

Several articles regarding analyses of the patient advocacy concept were identified in this literature review. Baldwin completed a concept analysis of patient advocacy and identified three defining attributes of this concept: 1) providing a therapeutic nurse-patient relationship in which to secure the patient's freedom and self-determination; 2) promoting and protecting the patient's rights to be involved in decision-making and informed consent; and 3) acting as an intermediary between patients, their families or significant others, and as a liaison between patients and healthcare providers. Baldwin summarized these three attributes as: 1) valuing: described as a nurse empowering a patient's freedom and self-determination; 2) apprising: promoting the nurse's role of informing, advising, and providing education; and 3) interceding: a term that described the nurse's role in assisting patients to overcome barriers for healthcare needs [12].

In similar research, Bu and Jezewski completed a concept analysis aimed at creating a mid-ranged theory of patient advocacy. They described three patient advocacy attributes including: 1) safeguarding patient's autonomy; 2) acting on behalf of the patients and 3) championing social justice in the provision of healthcare. The authors also suggested nurses should be aware of which patients need advocacy, what the patient's best healthcare interest is, and what actions are needed in particular patient situations [13].

Nutbeam also recognizes autonomy as a notable attribute of patient advocacy that includes informing the patient about all aspects of their medical diagnosis with a goal of increased health literacy. This attribute provides patients with knowledge about their diagnosis enhancing their ability to make informed decisions within the healthcare systems. Another attribute of patient advocacy is respecting the patient's decision regarding healthcare [22]. This attribute enables the patient to have a sense of control over healthcare decisions and assuring individual needs are met [23].

Mallik discussed the need for definitions and models that involve the patient advocacy concept, how this concept is an integral role of the professional nurse, and how nurses are in a pivotal position to advocate. The author suggested further research should be directed toward empirically examining the role of the patient advo- 
cate from both a healthcare leader and practicing nurse perspective [24].

MacDonald analyzed literature associated with relational ethics and advocacy in nursing. She performed this qualitative review to better understand advocacy in the nursing profession. Results of this research suggested that nurses must continue to learn more about relational contexts as these may influence nursing advocacy interventions [25].

\subsection{Nurses' Perspectives of Patient Advocacy}

Several authors have examined patient advocacy from a nurses' perspective. Results from one study describes patient advocacy as the nurse providing effective therapeutic communication with their patient, sharing a common humanity with their patients, identifying individual patient cultural considerations and patient advocacy from both a reactive and proactive perspective [26].

Foley, Minick and Kee identified an overall theme of safeguarding that includes four areas of advocacy: 1) advocating as protecting: including such factors as inexperienced practitioners and incorrect surgeries; 2) advocating as attending the whole person: requiring the nurse to comprehend the medical and social aspects of the patient; 3) advocating as being the person's voice: needed when the patient was not able to verbalize concerns; and 4) advocating as preserving personhood: related to the nurse's personal interactions with their patients [27]. Two years later these authors conducted similar research to identify patient advocacy roles and how nurses have developed in these roles. Nurse responses from this research included three themes: 1) Who I Am (personal core values); 2) Watching Other Nurses Interact with Patients (observing how other nurses interacted with patients and then talking to the nurses about their interactions) and 3) Gaining confidence (working with mentors to gain valuable experience) [4].

In a study by Hanks, nursing advocacy perspectives from Medical-Surgical nurses were examined. Results of this study included an overwhelming response of nurses educating the patient and family. Other nurse responses included communicating with other members of the healthcare team, questioning and assuring care, and evaluating the patient's health decisions [28].

In an article by Schwartz, the author described the need for advocacy, the role of advocacy, and who should advocate for patients. As for who should advocate, Schwartz identified several potential individuals including patients, friends, family, professional advocates, and physicians. The author further clarified that literature demonstrated the need for advocacy (especially for vulnerable patients) and suggested advocates should be assigned and trained to protect patient's rights and decisions [29].

The results of these nurse perspective studies present three advocacy themes including effective nurse-patient communication patterns; assuring patients receive individual health related education and recognizing the patients' healthcare decisions.

\subsection{Patient Advocacy with Culturally Diverse Patient Populations}

Research has shown that patients from culturally diverse backgrounds enter the healthcare system with a myriad of issues including medical mistrust, socioeconomic disparities, and inadequate health literacy [30]-[36]. These issues may impede favorable health outcomes. Additionally, patients who are new to healthcare systems, may be overwhelmed by healthcare system complexities; obscuring their view of potential benefits. These patients may not take advantage of the care they need, which will lead to an increased rate of chronic disease and health disparities.

The importance for nurses to recognize and deliver culturally appropriate care is especially important in today's ever evolving patient population [37]-[40]. Nurses who understand patient advocacy strategies for culturally diverse patients provide a unique vantage point from which to facilitate trust, improve communication patterns, and reduce chronic diagnosis rates.

During this literature review, only one study was identified examining personal cultural competence perspectives from nurses. This research, that included 179 nurses from a rural state, utilized the Inventory for Assessing the Process of Cultural Competence instrument to explore the relationship between cultural competence and education preparation. Results of the study indicated that more than $80 \%$ of the nurse participants did not consider themselves culturally competent [41].

\subsection{Patient Advocacy in Nursing Curricula}

While professional nurses embrace the concept of patient advocacy, the foundations of this concept must be in- 
corporated into nursing education curricula. Nursing students who have patient advocacy instilled throughout their curricula have an increased understanding of patient advocacy roles and how to apply this concept in practice [42].

In a study to investigate ethical reasoning from nursing students, researchers discovered an overriding theme of "in the process of becoming" which included several areas detailing patient advocacy responsibilities as a professional nurse [43]. In research to examine nursing student's experiences while caring for terminally ill patients, results included a theme of "helplessness experienced by nursing students regarding their role as patient advocates" [44]. Students explained this theme as being unaware of their patient's prognosis, not having a sense of power to increase their patient's pain medication, and a feeling of helplessness for their patient's last wishes [44]. Student nurses' perspectives on patient advocacy suggest this concept should continue to be delivered in nursing curricula to better prepare professional nurses for practice.

\subsection{Negative Effects of Patient Advocacy}

Although most articles in this literature review present positive consequences of patient advocacy, research has shown that nursing advocacy can result in negative consequences that include disagreements between the patient and nurse or between the physician and nurse [45]. While the professional nurse can play a key role in patient advocacy, one author suggests that advocacy interventions may need to be fully considered before implementation. Hyland examined patient autonomy and its relationship to the nurse's role as an advocate. The author concluded nurse advocates may place themselves at both professional and personal risk. Hyland made a strong case that while nurses must recognize the need to advocate for their patients, they must also respect the patient's right to autonomy [46].

\subsection{Patient Advocacy Empirical Referents}

While the concept of patient advocacy is recognized in published literature; instruments to measure this concept are somewhat limited. Moreover, at this time there are no measurements examining patient perceptions of advocacy, such as how advocacy was applied to their health encounter. Measuring advocacy from a patient's perspective would provide valuable information in identifying individual and cultural needs of patients and their medical diagnosis. These measurements would assist researchers in identifying the effectiveness of interventions utilized, leading to improved nurse-patient relationships and positive healthcare encounters.

Hanks introduced research to develop and test the Protective Nursing Advocacy Scale (PNAS). The PNAS measures protective nursing advocacy within four subscales to include: 1) Acting as Advocate; 2) Work Status and Advocacy Actions; 3) Environment and Educational Influences and 4) Support and Barriers to advocacy. Hanks recommends this newly developed instrument be used in nursing curricula to measure educational progression and how patient advocacy effects patient safety [21].

The Patient Self Advocacy Scale (PSAS) measures self-advocacy within three areas: 1) increased illness and treatment education; 2) increased assertiveness in healthcare interactions and 3) increased potential for non-adherence. Researchers have recommended the PSAS be used to determine patient communicative behaviors to analyze reasons patients are proactive in their health decisions and to explore activism within the patient-physician relationship [47].

Using patient satisfaction scales could also be considered to effectively measure patient advocacy. The LaMonica-Oberst Patient Satisfaction Instrument (LOPSS) examines three nursing care areas: 1) interpersonal support; 2) good impression; and 3) dissatisfaction with nursing care [48]. The Patient Satisfaction Instrument (PSI) is a similar survey that measures the nurse's technical and professional abilities, nurse-patient education relationships, and trust within the nurse-patient relationship [49]. Utilizing both the LOPSS and PSI could be used to gather key advocacy data from a patient's perspective such as how well patients were educated about a diagnosis, how nurses respected the patient's healthcare choices, and then acted on behalf of the patient's decision.

\section{Discussion}

Patient advocacy must be initiated at the beginning of a patient's healthcare encounter. To promote this, the nurse needs to provide a foundation of trust in the nurse-patient relationship that encourages patients to express their healthcare concerns, beliefs, and goals. The nurse must embrace the individual needs of the patient and then advocate for the patient's decisions. Nurses who incorporate these interventions will be recognized as 
trusted healthcare professionals among patients, their families, and the healthcare provider network.

Some healthcare professionals may view patient advocacy as simply acting on behalf of patients. While this is an important aspect of the concept and is evident throughout the literature, advocacy entails much more as nurses and other healthcare professionals care for culturally diverse patients with individual needs. These patient advocacy responsibilities include assuring that patients understand their medical diagnosis and treatment regimen, listening to the patients' concerns, and respecting their healthcare decisions. All healthcare providers must understand the importance of informing the patient about available healthcare options and advocating for the patient's decisions rather than acting only on what the healthcare professional may believe is best for the patient.

Providing patient advocacy will continue to enhance healthcare encounters and outcomes. This will be evident in a variety of healthcare environments including hospital emergency departments, intensive care units, outpatient settings such as dialysis units and wellness clinics. The need for patient advocacy will continue to grow as healthcare consumers from diverse populations will require more information and control about the healthcare they receive.

\section{Affordable Care Act}

On March, 23, 2010, President Barack Obama signed public law 111 - 148: the Patient Protection and Affordable Care Act. This national legislation allows quality, affordable healthcare for all Americans and provides numerous healthcare benefits such as reasonable health insurance rates, no lifetime or annual limits, coverage of preventive health services and immediate access to insurance for those with pre-existing conditions [50].

As a result of this legislation, patient populations from diverse backgrounds including 6.8 million uninsured African Americans, 10.2 million uninsured Latinos, and 2 million uninsured Asian Americans and Pacific Islanders now have new healthcare opportunities. In the past, these patient populations may not have had these opportunities because of high health insurance costs or other socio-economic concerns [51].

\section{Conclusions}

While literature supports nurses having a key role in providing advocacy, this review of the patient advocacy concept has revealed three major gaps: 1) the lack of a professionally recognized patient advocacy definition; 2) inadequate tools to measure advocacy from a patient's perspective and 3) the increasing need for nurses to be culturally aware of patient's needs.

A patient advocacy definition must include the importance of creating and maintaining a trusting patient healthcare professional relationship. Assuring clear communication between the patient and healthcare professional is critical to empower patients to make their own healthcare decisions. These communication patterns must be based on a well-defined understanding of the facts, implications, and future consequences of medical, nursing, and health related interventions and outcomes.

With a professionally recognized patient advocacy definition, nursing researchers will be able to develop useful patient advocacy measurements. Further studies utilizing similar instruments (nursing advocacy, patient self-advocacy, and patient satisfaction) could be helpful in designing measurements that will examine patient's perceptions of advocacy during their healthcare encounter. Measuring advocacy from a patient's perspective will provide valuable information about the individual health needs of all patients, including culturally diverse populations, resulting in better health outcomes.

When exploring nurses' perspectives of patient advocacy, only one article included the importance of providing culturally appropriate care [26]. More emphasis should be placed on nurses identifying and providing this type of care as patient populations are rapidly becoming more diverse. Additionally, due to limited studies measuring nurses’ cultural competence; nursing leaders must consider placing high priorities on recognizing the need for and delivering cultural awareness education to practicing nurses, especially with the recent implementation of the Affordable Care Act. Providing this education is critical as all patients deserve an understanding of their personal health concerns, available treatment regimens, and an advocate that understands their personal health decisions.

Patient advocacy and cultural awareness education must continue to gain momentum in today's healthcare environments and in nursing curricula. Healthcare leaders that embrace and deliver these important interventions will observe higher patient satisfaction scores and lower health disparity rates among all populations within their communities. 


\section{Author Contributions}

Ronnebaum, E.: Concept of this study, identification, selection and interpretation of literature. Drafting and preparation for publication.

Schmer, C.: Drafting and preparation for publication.

\section{Conflict of Interest}

The authors declare that they have no competing interests.

\section{References}

[1] Sanders-Thompson, V., Talley, M., Caito, N. and Kreuter, M. (2009) African-American Men’s Perceptions of Factors Influencing Health-Information Seeking. American Journal of Men’s Health, 3, 6-15. http://dx.doi.org/10.1177/1557988307304630

[2] Curtin, L. (1979) The Nurse as Advocate: A Philosophical Foundation for Nursing. ANS/Ethics and Values, 1, 1-10.

[3] Mahlin, M. (2010) Individual Patient Advocacy, Collective Responsibility and Activism within Professional Nursing Associations. Nursing Ethics, 17, 247-254. http://dx.doi.org/10.1177/0969733009351949

[4] Foley, B.J., Minick, P. and Kee, C. (2002) How Nurses Learn from Advocacy. Journal of Nursing Scholarship, 34, 181-186. http://dx.doi.org/10.1111/j.1547-5069.2002.00181.x

[5] Young, D.A. (1995) Florence Nightingale’s Fever. British Medical Journal, 311, 1697-1700. http://dx.doi.org/10.1136/bmj.311.7021.1697

[6] Nightingale, F. (1859) Notes on Nursing: What It Is and What It Is Not. Harrison and Sons, London. (Commemorative Addition, 1992, Lippincott Williams and Wilkins, Philadelphia).

[7] American Nurses Association (ANA) (2014) Code for Nurses with Interpretive Statements. http://www.nursingworld.org

[8] American Nurses Association (ANA) (1985) Code for Nurses with Interpretive Statements. American Nurses Association, Kansas City.

[9] Gadow, S. (1980) Existential Advocacy: Philosophical Foundations of Nursing. NLN Publications, Washington DC.

[10] Kohnke, M. (1980) The Nurse as Advocate. American Journal of Nursing, 80, 2038-2040.

[11] Watson, M.J. (1988) New Dimensions of Human Caring Theory. Nursing Science Quarterly, 1, 175-181. http://dx.doi.org/10.1177/089431848800100411

[12] Baldwin, M.A. (2003) Patient Advocacy: A Concept Analysis. Nursing Standard, 17, 33-39. http://dx.doi.org/10.7748/ns2003.02.17.21.33.c3338

[13] Bu, X. and Jezewski, M.A. (2007) Developing a Mid-Range Theory of Patient Advocacy through Concept Analysis. Journal of Advanced Nursing, 57, 101-110. http://dx.doi.org/10.1111/j.1365-2648.2006.04096.x

[14] Smith, A.P. (2004) Patient Advocacy: Roles for Nurses and Leaders. Nursing Economics, 22, 88-90.

[15] Legal Dictionary-The Free Dictionary (2014) Advocacy Definition. http://www.thefreedictionary.com/advocacy

[16] Hoffman, P. and Stephens, B. (2013) International Human Rights Cases under State Law and in State Courts. UC Irvine Law Review, 3, 9.

[17] Selbin, J. and Cummings, S. (2013) "Poverty Law” International Encyclopedia of Social and Behavioral Sciences. 2nd Edition, Elsevier, San Francisco.

[18] American Psychological Association (APA) (2014) What Do We Mean by “Advocacy”? http://www.apa.org/about/gr/advocacy/why.aspx

[19] Bybee, D. and Sullivan, C. (2002) The Process through Which an Advocacy Intervention Resulted in Positive Change for Battered Women Over Time. American Journal of Community Psychology, 30, 103-132. http://dx.doi.org/10.1023/A:1014376202459

[20] Andrews, K. and Edwards, B. (2004) Advocacy Organizations in the U.S. Political Process. Annual Review of Sociology, 30, 479-506. http://dx.doi.org/10.1146/annurev.soc.30.012703.110542

[21] Hanks, R. (2010) Development and Testing of an Instrument to Measure Protective Nursing Advocacy. Nursing Ethics, 17, 255-267. http://dx.doi.org/10.1177/0969733009352070

[22] Nutbeam, D. (2008) The Evolving Concept of Health Literacy. Social Science and Medicine, 67, 2072-2078. http://dx.doi.org/10.1016/j.socscimed.2008.09.050

[23] Barry, M. and Edgman-Levitan, S. (2012) Shared Decision Making-The Pinnacle of Patient-Centered Care. New 
England Journal of Medicine, 366, 780-781. http://dx.doi.org/10.1056/NEJMp1109283

[24] Mallik, M. (1997) Advocacy in Nursing-A Review of the Literature. Journal of Advanced Nursing, 25, 130-138. http://dx.doi.org/10.1046/j.1365-2648.1997.1997025130.x

[25] MacDonald, H. (2007) Relational Ethics and Advocacy in Nursing: Literature Review. Journal of Advanced Nursing, 57, 119-126. http://dx.doi.org/10.1111/j.1365-2648.2006.04063.x

[26] Snowball, J. (1996) Asking Nurses about Advocating for Patients: “Reactive” and "Proactive” Accounts. Journal of Advanced Nursing, 24, 67-75. http://dx.doi.org/10.1046/j.1365-2648.1996.01719.x

[27] Foley, B.J., Minick, P. and Kee, C. (2000) Nursing Advocacy during a Military Operation. Western Journal of Nursing Research, 22, 492-507. http://dx.doi.org/10.1177/01939450022044548

[28] Hanks, R. (2010) The Medical-Surgical Nurse Perspective of Advocate Role. Nursing Forum, 45, 97-107. http://dx.doi.org/10.1111/j.1744-6198.2010.00170.x

[29] Schwartz, L. (2002) Is There an Advocate in the House? The Role of Health Care Professionals in Patient Advocacy. Journal of Medical Ethics, 28, 37-40. http://dx.doi.org/10.1136/jme.28.1.37

[30] Hammond, W. (2010) Psychosocial Correlates of Medical Mistrust among African-American Men. American Journal of Community Psychology, 45, 87-106. http://dx.doi.org/10.1007/s10464-009-9280-6

[31] Ornelas, I., Amell, J., Tran, A., Royster, M., Armstrong-Brown, J. and Eng, E. (2009) Understanding African-American Men's Perceptions of Racism, Male Gender Socialization, and Social Capital through Photovoice. Qualitative Health Research, 19, 552-565. http://dx.doi.org/10.1177/1049732309332104

[32] Wexler, R., Elton, T., Pleister, A. and Feldman, D. (2009) Barriers to Blood Pressure Control as Reported by AfricanAmerican Patients. Journal of the National Medical Association, 101, 597-603.

[33] Bynum, S., Davis, J., Green, B. and Katz, R. (2012) Unwillingness to Participate in Colorectal Cancer Screening: Examining Fears, Attitudes, and Medical Mistrust in an Ethnically Diverse Sample of Adults 50 Years and Older. American Journal of Health Promotion, 26, 295-300. http://dx.doi.org/10.4278/ajhp.110113-QUAN-20

[34] Weissa, T., Weinberger, M., Holland, J., Nelson, C. and Moadel, A. (2012) Falling through the Cracks: A Review of Psychological Distress and Psychosocial Service Needs in Older Black and Hispanic Patients with Cancer. Journal of Geriatric Oncology, 3, 163-173. http://dx.doi.org/10.1016/j.jgo.2011.12.001

[35] Sheppard, V., Mays, D., LaVeist, T. and Tercyak, K. (2012) Medical Mistrust and Self-Efficacy Influence Black Women's Level of Engagement in BRCA 1/2 Genetic Counseling and Testing. Journal of the National Medical Association, 105, 17-22.

[36] Sentell, T. and Braun, K. (2012) Low Health Literacy, Limited English Proficiency, and Health Status in Asians, Latinos, and Other Racial/Ethnic Groups in California. Journal of Health Communication: International Perspectives, 17, 82-99. http://dx.doi.org/10.1080/10810730.2012.712621

[37] Breier-Mackie, S. (2007) Cultural Competence and Patient Advocacy: The New Challenge for Nurses. Gastroenterology Nursing, 30, 120-122. http://dx.doi.org/10.1097/01.SGA.0000267933.36748.e4

[38] Campinha-Bacote, J. (2011) Delivering Patient-Centered Care in the Midst of a Cultural Conflict: The Role of Cultural Competence. The Online Journal of Issues in Nursing, 16, Manuscript 5.

[39] Caplan, S., Escobar, J., Paris, M., Alvidrez, J., Dixon, J., Desai, M., Scahill, L. and Whittemore, R. (2012) Cultural Influences on Causal Beliefs about Depression among Latino Immigrants. Journal of Transcultural Nursing, 24, 68-77. http://dx.doi.org/10.1177/1043659612453745

[40] Douglas, M., Uhl Pierce, J., Rosenkoetter, M., Callister, L., Hattar-Pollara, M., Lauderdale, J., Miller, J., Milstead, J., Nardi, D. and Pacquiao, D. (2009) Standards of Practice for Culturally Competent Nursing Care: A Request for Comments. Journal of Transcultural Nursing, 20, 257-269. http://dx.doi.org/10.1177/1043659609334678

[41] Seright, T. (2007) Perspectives of Registered Nurse Cultural Competence in a Rural State-Part II. Online Journal of Rural Nursing and Health Care, 7, 57-69.

[42] Altun, I. and Ersoy, N. (2003) Undertaking the Role of Patient Advocate: A Longitudinal Study of Nursing Students. Nursing Ethics, 10, 462-471. http://dx.doi.org/10.1191/0969733003ne628oa

[43] Callister, L., Luth, K., Thompson, P. and Memmott, R. (2009) Ethical Reasoning in Baccalaureate Nursing Students. Nursing Ethics, 16, 499-510. http://dx.doi.org/10.1177/0969733009104612

[44] Tatano-Beck, C. (1997) Nursing Students' Experiences Caring for Dying Patients. Journal of Nursing Education, 36, 408-415.

[45] Vaartio, H., Leino-Kilpi, H., Salantera, S. and Suominen, T. (2006) Nursing Advocacy: How Is It Defined by Patients and Nurses, What Does It Involve and How Is It Experienced? Scandinavian Journal of Caring Sciences, 20, 282-292. http://dx.doi.org/10.1111/j.1471-6712.2006.00406.x

[46] Hyland, D. (2002) An Exploration of the Relationship between Patient Autonomy and Patient Advocacy: Implications 
for Nursing Practice. Nursing Ethics, 9, 472-482. http://dx.doi.org/10.1191/0969733002ne537oa

[47] Brashers, D., Haas, S. and Neidig, J. (1999) The Patient Self-Advocacy Scale: Measuring Patient Involvement in Health Care Decision-Making Interactions. Health Communication, 11, 97-121. http://dx.doi.org/10.1207/s15327027hc1102_1

[48] O’Connell, B., Young, J. and Twigg, D. (1999) Patient Satisfaction with Nursing Care: A Measurement Conundrum. International Journal of Nursing Practice, 5, 72-77. http://dx.doi.org/10.1046/j.1440-172x.1999.00158.x

[49] Hinshaw, A.S. and Atwood, J.R. (1982) A Patient Satisfaction Instrument: Precision by Replication. Nursing Research, 31, 170-175. http://dx.doi.org/10.1097/00006199-198205000-00011

[50] Public Law 111-148, Patient Protection and Affordable Care Act, 23 March 2010.

[51] Health and Human Services. HHS.gov. (2014) HealthCare. http://www.hhs.gov/healthcare/facts/factsheets/index.html 